\title{
The ZooCAM, a new in-flow imaging system for fast onboard counting, sizing and classification of fish eggs and metazooplankton
}

\author{
Colas Florent ${ }^{1,{ }^{*}}$, Tardivel Morgan ${ }^{1}$, Perchoc Jonathan ${ }^{1}$, Lunven Michel ${ }^{1}$, Forest Bertrand ${ }^{1}$, \\ Guyader Gerard ${ }^{1}$, Danielou Marie-Madeleine ${ }^{1}$, Le Mestre Sophie ${ }^{1}$, Bourriau Paul ${ }^{1}$, Antajan Elvire ${ }^{1}$, \\ Sourisseau Marc ${ }^{1}$, Huret Martin ${ }^{1}$, Petitgas Pierre ${ }^{1}$, Romagnan Jean-Baptiste ${ }^{1, *}$ \\ * Corresponding authors : Florent Colas, email address : florent.colas@ifremer.fr ; Jean-Baptiste \\ Romagnan, email address : jean.baptiste.romagnan@ifremer.fr
}

\begin{abstract}
:
In this paper we present the ZooCAM, a system designed to digitize and analyse on board large volume samples of preserved and living metazooplankton (i.e. multicellular zooplankton) and fish eggs $>300$ $\mu \mathrm{m}$ ESD. The ZooCAM has been specifically designed to overcome the difficulties to analyse zooplankton and fish eggs in the framework of the PELGAS survey, and provide high frequency data. The ZooCAM fish eggs counts were comparable to those done with a dissecting microscope. The ZooCAM enabled the accurate prediction and fast on board validation of staged anchovy and sardine eggs in almost real time after collection. A comparison with the ZooScan, on a more complex zooplanktonic community, provided encouraging results on the agreement between the 2 instruments. ZooCAM and ZooScan enabled the identification of similar communities and produced similar total zooplankton abundances, size distributions, and size spectra slopes, when tested on the same samples. However these results need to be further refined due to the small number of samples used to compare the two instruments. The main ZooCAM drawback resides in a slight but sensible underestimation of abundances and sizes, and therefore individual and community biovolumes. The ZooCAM have been successfully deployed over 4 years, on numerous surveys without suffering any major failure. When used in line with the CUFES it provided high resolution maps of staged fish eggs and zooplanktonic functional groups. Hence the ZooCAM is an appropriate tool for the development of on board, high frequency, high spatial coverage zooplanktonic and ecosystemic studies.
\end{abstract}




\section{Highlights}

- The ZooCAM is a new in-flow imaging system for fast onboard counting, sizing and classification of fish eggs and metazooplankton. The ZooCAM has been used on-board for 4 years without suffering any failure and enabled the analysis $\sim 10,000$ samples so far (CUFES, WP2 and other plankton nets). - The ZooCAM provided staged fish eggs counts that were equivalent to those traditionally done by microscopic examination. These data were used for 2016 and 2017 anchovy and sardine stocks estimations in the Bay of Biscay (DEPM method) - The ZooCAM enable the real time, on-board, imaging of complex communities zooplankton samples and provide results comparable to on-land, well established counterpart, the ZooScan. - The ZooCAM is a valuable tool to improve zooplanktonic studies, in term of spatial coverage and temporal frequency, to perform ecosystemic studies.

Keywords : ZooCAM, in-flow imaging, fish eggs, zooplankton, ecosystemic survey 


\section{Introduction}

In the last decade, the European Commission encouraged member states to monitor marine ecosystems (Marine Strategy Framework Directive, MSFD: 2008/56/EC) to achieve and maintain Good Environmental Status (GES). MSFD promotes ecosystemic monitoring programs that would serve as a basis for the development of ecosystemic sustainable management. Ecosystemic monitoring implies (i) the capacity to monitor the whole spatial range of the ecosystem at appropriate frequency and spatial resolution to capture relevant ecological processes, and (ii) observe all the compartments of the ecosystem simultaneously, at the relevant scale for each compartment. The PELGAS survey has been developed since 2000 in the Bay of Biscay. The survey now provides spatialized data on numerous pelagic compartments of the Bay of Biscay ecosystem (hydrology, phytoplankton, mesozooplankton, fish and megafauna), informing fish stock and ecosystem-based management, and supporting ecosystem science (Doray et al., this issue).

Monitoring physical and biogeochemical parameters at high frequency and spatial resolution is now possible by the use of autonomous platforms such as gliders (Schofield et al., 2007; Queste et al., 2016) or autonomous profilers (de Fommervault et al., 2015). Conversely, biological variables, i.e. plankton or fish dynamics, remain hard to capture at high spatio-temporal resolution. Monitoring the biota often requires the deployment of ship based sampling devices, i.e. oceanographic bottles, plankton nets and pelagic and bottom trawls, and subsequent time consuming analyses by human examination of samples. Nevertheless, in-situ, semi-automated, high frequency phytoplankton long term observation have been achieved (Thyssen et al., 2014; Campbell et al., 2013) using imaging in-flow instruments (i.e. Olson \& Sosik, 2007) in coastal sites. High spatio-temporal frequency observation of phytoplanktonic community proxies is now possible through the use of remote sensing products coupled with discrete in situ pigment measurement (Uitz et al., 2006; McClain, 2009). In a similar manner, direct and indirect observation of fishes are now routinely performed in the framework of stock assessment surveys and ecosystemic surveys such as PELGAS (Doray et al., this issue, Doray et al., 2014) by the use of acoustic techniques and midwater trawls hauls, at the regional scale. Data on birds (Certain et al., 2008) and top predators, essentially marine mammals, are now available thanks to dedicated monitoring programs, at the relevant scales (Mannocci et al., 2015). Despite recent efforts, the zooplankton remain a biological compartment that is still hard to analyse at the relevant spatial scales and frequencies, at a reasonable biological/taxonomical resolution, in the framework of marine ecosystemic, empirical, observation based, or modelling based, studies (Mitra et al., 2014). The Continuous plankton Recorder (CPR) program which exists since the 1930's is an example of what can be done to 
monitor zooplankton efficiently (Richardson et al., 2004). Nonetheless, zooplankton analysis still represent a major bottleneck in the design of truly ecosystemic studies of marine systems.

In the past decade, imaging has become an operational solution to acquire meso- and macrozooplankton data at fine spatial scale and/or high frequency (e.g. Romagnan et al., 2015) by the development of numerous dedicated instruments (Davis et al., 2005; Benfield et al., 2007; Gorsky et al., 2010; Picheral et al. 2010; Cowen and Guigand, 2008), and dedicated analytical methods (Failletaz et al., 2016; Hirata et al., 2016; Gonzalez et al., 2016). Compared to other methods to analyse zooplankton such as microscopic examination or optical methods (e.g. Optical Plankton Counter, OPC \& Laser-OPC) imaging enable a good but coarse taxonomic identification coupled with the precise size measurement of numerous objects in a short time. Yet, sampling and analysing zooplankton with imaging remain challenging because the sampled volume (imaged volume) and image resolution do not always enable quantitative estimates of key zooplankton variables (see Romagnan et al., 2016 for a review addressing the quantitative analysis of zooplankton using imaging techniques). The combination of net sampling with bench-top imaging is an efficient approach because it enables the quantitative sampling (up to tens of cubic meters) and an accurate control of the image generation and resolution (Gorsky et al., 2010) compared to in-situ imaging. But these advantages are minored by the coarse spatial resolution achieved by net sampling.

The ZooScan is one of the main commercially available bench-top imaging instrument dedicated to the analysis of zooplankton (Gorsky et al., 2010). It enables the analysis of $\sim 3000$ objects, corresponding to 2-3 samples per day (Romagnan et al., 2016). However, it has to be stable during the scanning process and therefore cannot be used onboard a research vessel. Other scanners or photographic camera have been tested (e.g. Bachiller et al., 2012) but suffer the same drawback. The FlowCAM which takes microscope images of particles in a water flow (Sieracki et al., 1998) is an alternative to the ZooScan. It is routinely used for phytoplankton analysis and can be used on board (Jenkins et al., 2016; Zarauz et al., 2009). It has also been used to analyze metazooplankton on a limited size range $(<1 \mathrm{~mm})$ that do not encompass the whole metazooplanktonic community (Le Bourg et al., 2015). Yet, FlowCAM analyses duration may become excessively long for concentrated samples as they require subsampling and large dilution to limit overlapping organisms and the maximum FlowCAM flow rate does not exceed $20 \mathrm{~mL} / \mathrm{min}$ (Fluid Imaging documentation).

In this paper we will present the ZooCAM, a system designed to image and analyze on board large volume samples of living metazooplanktonic organisms and fish eggs larger than 300 $\mu \mathrm{m}$ ESD. The ZooCAM has been designed to overcome the difficulties to analyse zooplankton and fish eggs in the framework of the PELGAS survey. PELGAS provides data for DEPM (Daily Egg Production Method, Lasker, 1985; Stratoudakis et al., 2006; Bernal et al., 2011). DEPM is based on age-staged fish eggs data. One essential objective for the ZooCAM development was the fast 
counting and accurate identification of staged fish eggs. The development specifications were then: on board use and time effectiveness in analysing large volume of water to enable high frequency quantitative analysis of zooplankton and fish eggs, and coupling to an efficient classification software, for a complete analysis and sorting of fish eggs at the end of the survey. We will present the hardware, the software, and how the ZooCAM can provide data on fish eggs and zooplankton sampled during PELGAS surveys. The ZooScan is a good reference when considering benchtop imaging of zooplankton. A comparison of ZooCAM and ZooScan would therefore be an adequate benchmark to estimate the ZooCAM efficiency to provide sufficiently qualified data from in-flow imaged zooplankton samples. We will compare the results obtained with the ZooCAM and the ZooScan on key ecological variables i.e. individual and community abundances distributions, size distributions and biovolumes distributions, community size spectra slopes, and community functional groups composition.

\section{Material and Methods}

\section{ZooCAM hardware}

The ZooCAM features a fluidic module and an optical/imaging module (Fig. 1). On the prototype the imaging module is encased in a transparent box, while the fluidic module is mostly external. The fluidic module is made up of an external 5L cylindrical transparent polycarbonate tank in which the sample and filtered seawater are mixed and gently stirred by a meshed blade, in a step by step, back and forth rotating motion to minimize the sinking of particles. The bottom of the tank is funnel shaped and connected to a high volume peristaltic pump (Masterflex L/S series) by large diameter silicon tubing. The pump drives the seawater and the particles through the tubing to a flowcell were they are imaged. The pump flow speed can be manually adjusted between $0.281 . \mathrm{min}^{-1}$ and $1.71 . \mathrm{min}^{-1}$. The flowcell is a hard and transparent polycarbonate parallelepipoid of $100 \mathrm{~mm}^{2}$ square section. It is $5 \mathrm{~cm}$ long and positioned vertically to prevent particles from sinking and getting stuck to the cell walls.

The imaging module features a camera, the optical parts and the illumination system. The flowcell is mounted between the camera and the illumination system. The images are captured by a 1280 x 1024 pixels black and white USB 3.0 CCD camera (Thorlabs), whose pixel size is $5.3 \mu \mathrm{m}$, on which a telecentric $0.5 \mathrm{X}$ (Edmund optics) is mounted. Therefore a pixel in the object field (image acquired) corresponds to $10.6 \mu \mathrm{m}^{2}(5.3 \mu \mathrm{m} / 0.5)$. The iris of the objective is closed at its minimum opening diameter so the objective reaches $10 \mathrm{~mm}$ depth-of-field. Given the size of the $\mathrm{CCD}$ sensor, the size of the pixel, and the magnification, the imaged field is $13.6 \times 10.9 \mathrm{~mm}^{2}$. A spherical object of $1 \mathrm{~mm}$ diameter will be sampled by 36000 pixels. The illumination system is a 
red LED (Thorlabs) emitting in strobe mode flashes of $200 \mu$ s duration at a $15 \mathrm{~Hz}$ frequency (350 $\mathrm{mA}$ power or $170 \mathrm{~mW}$ optical power). A scattering plate and a lens of $75 \mathrm{~mm}$ focal length ensure a homogeneous irradiance of the flowcell. The camera acquisition speed is synchronized with the light source flash frequency and duration. Considering the imaged surface and the flowcell depth $(10 \mathrm{~mm})$, the seawater volume imaged is $1.2 \mathrm{ml}$ for each frame. After being imaged, the seawater and its content can be recovered in a bucket and a sieve of appropriate mesh size or discarded.

A

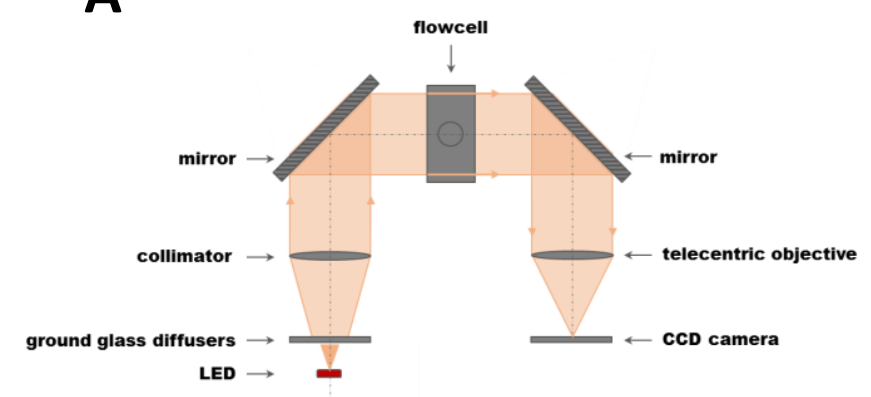

B

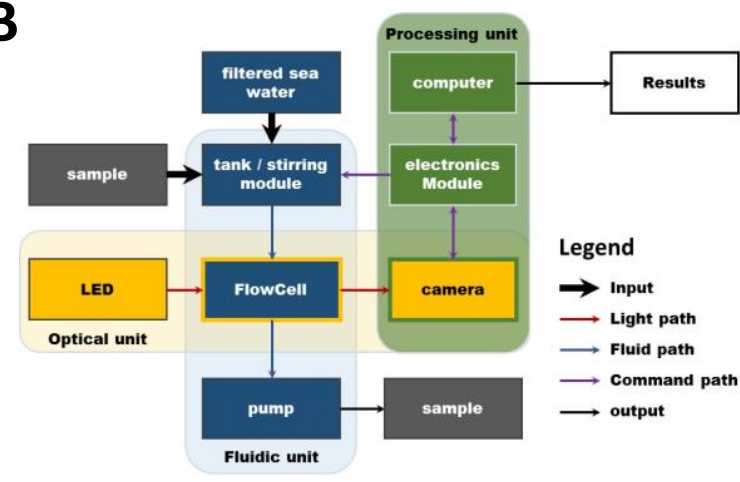

Fig. 1 Schematic of the ZooCAM system. A) Optical scheme. B) Functionnal diagram

\section{ZooCAM software}

The ZooCAM is controlled by a custom software developed in C\# (Csharp, Microsoft Visual Studio). The software controls and enables the synchronization of the pump, the stirring (in the tank), the illumination system and the camera. It provides all the necessary tools needed to analyse metazooplankton samples by imaging: acquisition of images, process images to get vignettes of individual objects and associated morphological features, and machine learning tools to perform semi-automatic identification of imaged objects. The software features a mouse operated user interface to run the tools listed above. Few basic metadata (gear used to sample, subsampling ratio, cruise name, geolocation) can also be input and associated to the digitized sample via the software before processing the acquired images. The core functions of the software are detailed below:

(i) Acquisition of images: Images are continuously acquired during the time the sample is drawn through the flowcell. For each sample, around 4000 non-overlapping images are recorded in an uncompressed tiff format $(1280 * 1024$ pixels $* 256$ grey levels, Black : 0 - White :255), covering the $5 \mathrm{~L}$ sample. The acquisition window enable to start and stop the stirring, the pump and the camera simultaneously or separately. The fluid flow is seen in real time in a separate window where instantaneous and average flow speeds, number of acquired images and acquisition time are monitored. 
(ii) Process of acquired images: Image analysis is performed using the MIL (Matrox Imaging Libray, Dorval, Québec, Canada). Each digitized sample is processed to get a set of features values which will be used for further automatic identification and sizing of particles, for each particle. The image processing is classical (Gorsky et al., 2010): background subtraction with a blank and empty background image originating from the digitized sample, binary tresholding, segmentation of Regions of Interests (ROIs, here particles, fish eggs and zooplanktonic organisms), and extraction of morphological features of each particle detected (Fig. 2). Fifty-two features are computed on each object (Table S1, supplementary online material). Image processing generates a set of black and white size scaled vignettes (one vignette for each object) and .pid file (asci) containing the features extracted for each object. The .pid file contains the metadata associated to the sample, the acquisition, and the processing steps.

(iii) Creation and evaluation of training sets: The software enable the creation of categorized learning sets that can be tested by cross-validation. The test produces confusion matrices to diagnose the confusions between predicted categories and evaluate the prediction efficiency. The ZooCAM software offers the same capabilities than that described in Gorsky et al., 2010 for creating and evaluating learning sets.

(iv) Prediction and validation of identification: The ZooCAM software proposes only the Random Forest algorithm (Breiman et al., 2001) which is an efficient method for predicting zooplankton identifications. It offers the same capabilities than that described in Gorsky et al., 2010 for validating the identifications and export the data.

Here it is worth noticing that the complete processing of a sample, from image acquisition to validation of predicted identification, can be done with the same single software.

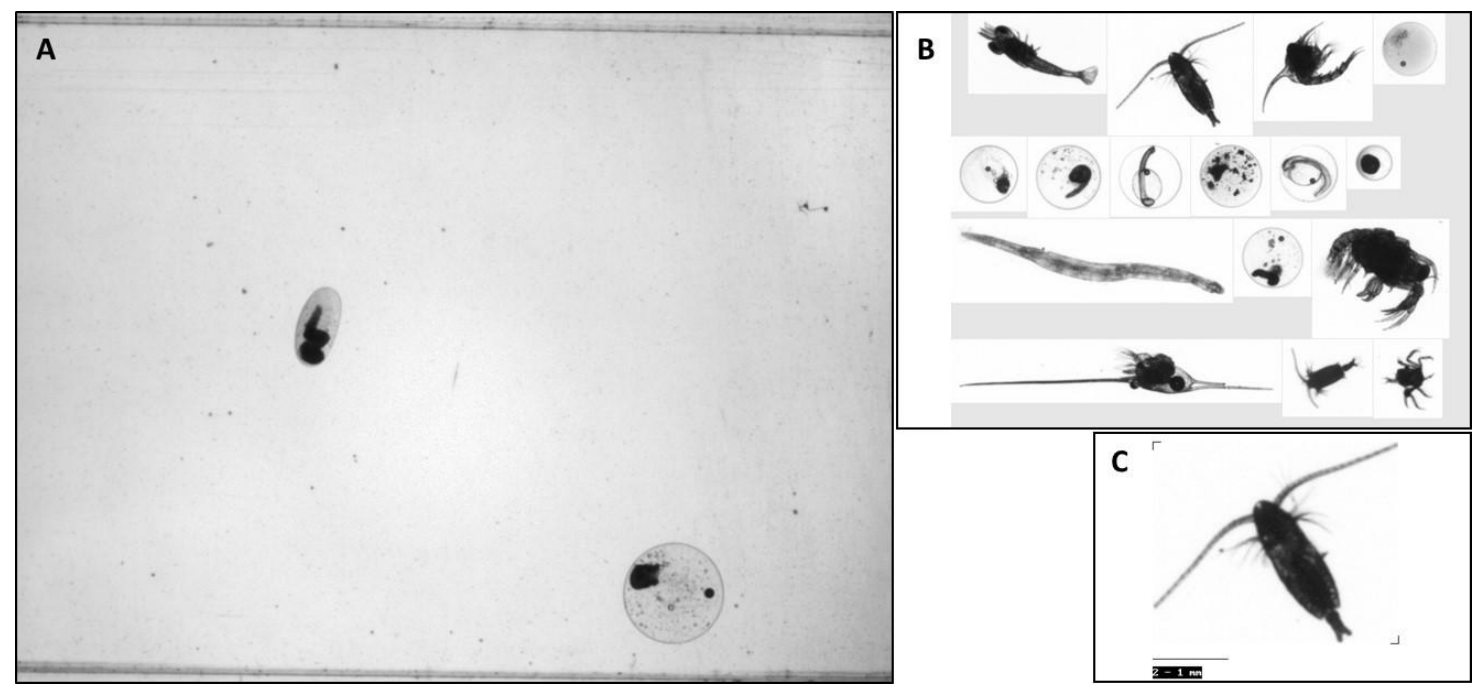


Fig.2 Illustration of the image outputs. A) raw image containing one anchovy egg (top) and one sardine egg (bottom), B) collage image, and C) vignette of segmented organism (copepod)

\section{Operational field testing}

The ZooCAM have been developed and tested since 2014 and generated scientifically qualified data of metazooplankton and fish eggs since 2015. Since the beginning the ZooCAM was used to analyse fish egg samples collected with a Continuous Underwater Fish Egg Sampler (CUFES, Checkley et al., 1997) at high frequency (one sample every 3 nautical mile e.g. PELGAS 2016, 639 samples). Fish eggs data were used in 2016 in the framework of fish stocks evaluation (ICES, 2017, WGACEGG report), and metazooplankton data are the basis of a project conducted at Ifremer since 2016 (Senn et al., 2016). The ZooCAM has already been operationally used during 10 surveys conducted by Ifremer on the R/V Thalassa: PELGAS (May 2014, 2015, 2016, 2017) and EVHOE (Oct.-Nov. 2015, 2016) in the Bay of Biscay, IBTS (Jan.-Feb. 2015, 2016, 2017) in the English Channel and southern North Sea, and CGFS (Sept.-Oct. 2016, English Channel).

\section{Validation of fish eggs abundances}

The capability of the system to enumerate fish eggs (Fig.3) was assessed by comparing results from traditional dissecting microscope counts to those obtained with the ZooCAM. Eleven samples of anchovy eggs were prepared to create a benchmark of quantities of anchovy eggs encountered in the field. These samples were analysed with the ZooCAM, and the consistency of counts along the range was estimated by fitting a linear regression on the dissecting microscope versus ZooCAM counts cloud of points (Fig.4).

A 23 categories learning set (12 eggs categories, Table 1) was built on CUFES selected samples from 2014 to test the ability of the ZooCAM to discriminate age-staged fish eggs during 2015 survey. The 11 referenced egg stages of Moser and Alhstrom (1985) and Alhstrom (1943) for anchovy and sardine eggs, respectively, were divided in 5 distinct stages for each species (Fig. 3), which was considered an acceptable trade-off between potential prediction error rates and required biological resolution, and need for efficient automatic sorting followed by visual validation (Culverhouse et al., 2003; Culverhouse, 2007; Gorsky et al., 2010). The learning set performances were tested by cross-validation. Basically the cross-validation works as follows: The first step is a random partitioning of the initial data set into $n$ equal fractions, here $n=5$. Then, $n-1$ fractions are used to compute the classification model and predict identifications on the remaining fraction. The prediction outputs are then compared to the true, known, identifications. This process can be repeated $m$-times, here 5 times. It generate 2 essential statistics: the recall, or true positives rate, i.e. the percentage of particles correctly predicted as belonging to a given category (best when close to 100), and the contamination, or false positive rate, i.e. the percentage of particles incorrectly 
predicted to belong to a given category (best when close to 0). See Gorsky et $a l$., 2010 for a more detailed description of the cross-validation process

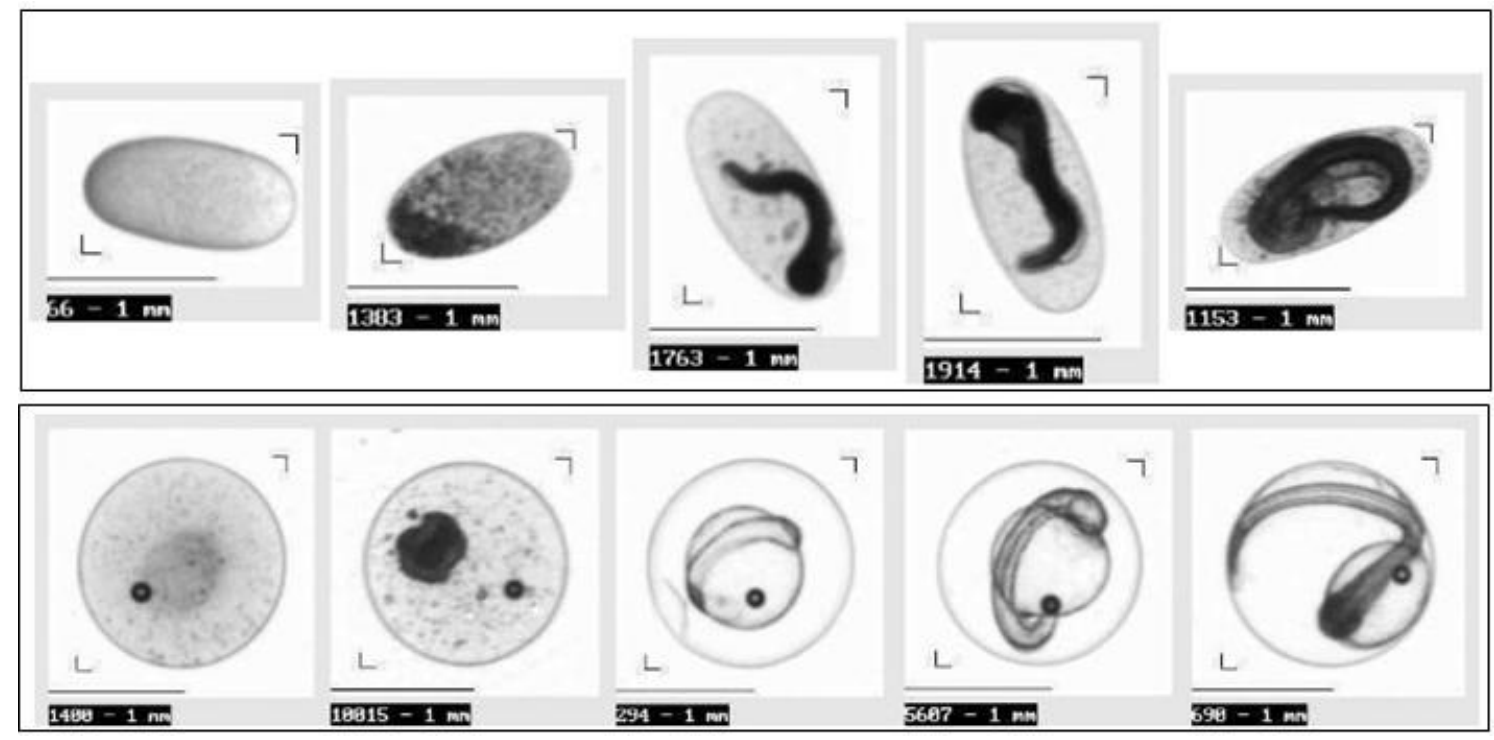

Fig. 3 Development stages identified for anchovy (top row, from left to right: stage 1, stage 23, stage 4-6, stage 7-8 and stage 9-11 after Moser and Ahlstrom (1985)) and sardine (bottom row, from left to right: stage 1, stage 2-3, stage 4-6, stage 7-8 and stage 9-11 after Ahlstrom (1943)).

\section{Caveats: Assessment of Touching Objects (TO) and 'Cut' objects}

In the case benchtop plankton scanners, TO are objects that physically touch each other and are segmented as one during the image analysis (Fig. S1). In the case of the ZooCAM, TO may not physically touch each other in the 3D flowcell volume, but the projection of their 2D silhouette on the CCD sensor may have at least one pixel in common. Hence they will be overlapping on the resulting raw image, and will be segmented as one single ROI. TO can be composed of 2 or more planktonic and/or non-planktonic objects. An increase in TO is expected as the concentration of particles in the processed sample increases. This effect was assessed by comparing the number of TO vignettes with the total number of vignettes per sample from 100 CUFES samples from PELGAS 2014 survey. An extensive review of biases induced by TO in plankton image datasets can be found in Vandromme et al., 2012.

Another limitation of in-flow imaging systems like the ZooCAM is the source of error in count and measurement originating from 'cut' objects i.e. that are partially out of an image. The more mature in-flow imaging systems are the FlowCAM, initially designed to image nano- and microplankton in the $2-200 \mu \mathrm{m}$ size range (Sieracki et al., 1998), and the Imaging FlowCytoBot designed to image objects in the same size fraction (Olson and Sosik, 2007). These previous studies poorly addressed the 'cut' objects issue. The large objects (for ZooCAM plankton and micronekton, $>2 \mathrm{~mm}$ ) can be cut at the image edges at the inlet or the outlet of the flowcell during the raw images acquisition. They are easily detected by their geographical positioning in the raw images, 
but their computed morphological features can be more or less biased depending on the extent of the part that is outside the image. It is important to account for them as large organisms may represent rare but key taxa in zooplanktonic communities, and influence size distributions such as Normalized Biomass - Size Spectra (NB-SS, Platt \& Denman, 1978; San Martin, 2005). These objects will be later referred to as 'cut' objects. The probability for an object to be cut was estimated with a numerical simulation. Virtual objects of varying sizes were randomly positioned in a simulated flowcell, and their probability to be cut as a function of size was estimated. These predictions were tested using imaged anchovy and sardine eggs of average length of $1.4 \mathrm{~mm}$ and 1.6 mm respectively (PELGAS 2015 set of CUFES samples, $\mathrm{n}=660$ ).

\section{Comparison of ZooCAM and ZooScan}

Nine zooplankton samples collected during the FROMVAR cruise with a WP2 net and previously analysed with a ZooScan were imaged with the ZooCAM to estimate the agreement and differences between the two imaging systems. The FROMVAR cruise was held in 2009 around the Ushant tidal front in the Northern part of the Bay of Biscay (Shultes et al., 2013). Samples were preserved on board with $4 \%$ tetraborate buffered formaldehyde and imaged subsequently back in the lab, on land. The FROMVAR ZooScan data were originally sorted into 25 categories (Shultes et $a l$. , 2013). For this study they were aggregated into 12 larger categories i.e. Appendicularia, Chaetognatha, Cladocera, Copepoda, Shrimp like, Gasteropoda, Thaliacea, Cnidaria, Siphonophora, Fish Eggs, Detritus (this category encompasses, detritic material, pieces of unidentified organisms, artefacts, out of focus objects, phytoplankton and bubbles) and TO. ZooCAM vignettes were sorted accordingly. Only the individuals belonging to planktonic categories (Detritus and TO were excluded) and larger than $300 \mu \mathrm{m}$ Equivalent Spherical Diameter (ESD) were considered for comparisons, because the ZooScan default lower size detection limit is $300 \mu \mathrm{m}$ ESD. ESD was calculated as follow:

$E S D=2 \times \sqrt{ }\left(\frac{\text { Area }}{\pi}\right)$

Where Area is the surface of the imaged objects in $\mu \mathrm{m}^{2}$.

The comparison of the data obtained with the two imaging systems was made in 3 steps:

(i) Comparison of coarse quantitative descriptive variables of the whole community, station by station: Total planktonic abundance (individuals per cubic meters of sampled seawater, ind. $\mathrm{m}^{-3}$ ); total planktonic biovolume, as estimated considering a spherical model (cubic millimeters of organisms per cubic meters of sampled seawater, $\mathrm{mm}^{3} \cdot \mathrm{m}^{-3}$, Vandromme et al., 2012); NB-SS slopes (Platt and Denman, 1978; Zhou, 2006); and size, measured as individual Equivalent Spherical Diameter (ESD) distributions. 
(ii) Comparison of community composition.

(iii) Comparison of size (ESD) and individual biovolumes distributions of planktonic particles, considering data pooled by organisms across the whole dataset.

Due to the small sample number for stations abundances and biovolumes comparisons $(n=$ 9), no statistical test was applied to illustrate the comparison. To estimate the agreement between the overall objects size distributions (ESDs), station by station (the distribution of one specific dataset, e.g. the ESD distribution of copepods, from ZooScan for a station compared with the distribution of the same specific dataset from ZooCAM for the same station), and taxa by taxa between the two imaging system, a two sided Wilcoxon rank sum test was used (Matlab ranksum function). It tests the null hypothesis stating that data in the vectors $\mathrm{x}$ and $\mathrm{y}$ are independent samples from identical continuous distributions with equal medians, against the alternative that they do not have equal medians. The test is equivalent to a Mann-Whitney $U$-test. It is applicable when the two distributions to compare do not have the same number of points (Hogg \& Tanis, 2006). At the $5 \%$ significance level, a $p$-value $<0.05$ means the null hypothesis is rejected, the 2 data vectors do not have equal medians. The difference between ZooScan and ZooCAM NB-SS slopes was tested using Analysis of Covariance (ANCOVA) and post hoc multiple pair-wise comparison ((Matlab aoctool and multcompare functions).

\section{Results}

\section{Prediction of fish eggs and metazooplankton}

Prediction performances were estimated by cross-validation on the learning set ( 5 folds, 5 iterations). The classifier performances for each groups averaged over five iterations of the cross validation process are presented in Table 1.

Anchovy and sardine egg stages 1 are best predicted, showing a true positive rate of $95.7 \%$ and $78.5 \%$ respectively, combined with the lowest contamination rates among anchovy and sardine eggs, $5.9 \%$ and $6.7 \%$ respectively (Table 1). The other anchovy eggs stages true positive rates ranged from $54.6 \%$ (stage 3 ) to $66 \%$ (stage 5) and the false positive rates ranged from $31 \%$ (stage 5) to $47.8 \%$ (stage 3 ). Anchovy eggs stage 3 show the lowest identification performances. The other sardine eggs stages true positive rates range from $88.8 \%$ (best, Stage2) to $16.8 \%$ (worst, Stage 4) and the false positive rates range from $22 \%$ (stage 2) to $59.1 \%$ (stage 4). Sardine eggs stage 4 show the lowest identification performances. Seventeen per cent of the sardine eggs were damaged, probably due to mechanical shocks during CUFES sampling (sardine eggs have a large perivitelline space that make them particularly fragile). The damaged sardine eggs were predicted 
separately from staged eggs, and were well predicted (true positive rate: $92.1 \%$, false positive rate: $15.7 \%)$.

The detection and prediction of large, spherical non-zooplanktonic particles such as Halosphaera and Noctiluca (phytoplanktonic organisms) and bubbles was efficient enough to sort them in specific categories to subsequently exclude them from the zooplankton data analyses and prevent their confusion with fish eggs. The prediction performances were also really good for Cladocera, fibers, and Euphausiacea. The higher variability of shapes and sizes in the Malacostraca, Detritus and Copepoda categories induced higher misidentification levels, without confusion with eggs. Without considering eggs stages, prediction performances for anchovy eggs showed a true positive rate of $95.5 \%$ and a contamination rate of $1.6 \%$. Without considering eggs stages, sardine eggs showed a true positive rate of $86.2 \%$ and a contamination rate of $1.6 \%$ (damaged eggs not considered).

After visual inspection and validation of predicted identifications (as recommended by Gorsky et al., 2010), ZooCAM eggs counts and dissecting microscope egg counts could be compared (Fig. 4), and eggs spatial distributions in May 2015 could be mapped over the entire bay of Biscay (see Fig. S1 for total anchovy eggs distribution).

Table 1. Classifier performances based on the comparison between the predicted and validated Pelgas 2015 CUFES samples. "Recall" is the true positives rate, i.e. the percentage of particles correctly classified as belonging to a given category (best when close to 100), and "Contamination" is the false positive rate, i.e. the percentage of particles incorrectly predicted to belong to a given category (best when close to 0 )

\begin{tabular}{|l|l|l|}
\hline Group & Recall & Contamination \\
\hline Bubbles & 98.7 & 5.4 \\
\hline Detritus & 81.2 & 12.6 \\
\hline Fibers & 97.7 & 2.9 \\
\hline Halosphaera & 96.0 & 5.7 \\
\hline Noctiluca & 99.0 & 1.1 \\
\hline Copepoda_large $(>1 \mathrm{~mm})$ & 81.5 & 27.2 \\
\hline Copepoda_small $(<1 \mathrm{~mm})$ & 85.5 & 15.6 \\
\hline Euphausiacea & 86.5 & 9.8 \\
\hline Malacostraca_large & 58.0 & 31.1 \\
\hline
\end{tabular}




\begin{tabular}{|l|l|l|}
\hline Cladocera & 92.0 & 11.9 \\
\hline Anchovy eggs stage 1 (1) & 95.7 & 5.9 \\
\hline Anchovy eggs stage 2 (2-3) & 60.0 & 35.7 \\
\hline Anchovy eggs stage 3 (4-6) & 54.6 & 47.8 \\
\hline Anchovy eggs stage 4 (7-8) & 58.9 & 41.5 \\
\hline Anchovy eggs stage 5 (9-11) & 66.0 & 31.0 \\
\hline Sardine eggs stage 1 (1) & 78.5 & 6.7 \\
\hline Sardine eggs stage 2 (2-3) & 88.8 & 22.0 \\
\hline Sardine eggs stage 3 (4-6) & 59.8 & 39.8 \\
\hline Sardine eggs stage 4 (7-8) & 16.8 & 59.1 \\
\hline Sardine eggs stage 5 (9-11) & 67.6 & 37.4 \\
\hline Sardine eggs damaged & 92.1 & 15.7 \\
\hline Other Fish egg & 95.6 & 5.5 \\
\hline Objects 'cut' & 100 & 0 \\
\hline
\end{tabular}

The agreement between ZooCAM and dissecting microscope counts is high (Fig. 4). The determination coefficient of the regression slope $\left(R^{2}\right)$ is 0.998 , the Pearson correlation coefficient is 0.999, and the regression slope is $>0.96$. The test of significance for slope and intercept (different from 1 and 0 , respectively), is negative ( $p$-value $>0.01)$, which underlines the statistical equivalence between counts from both methods. 


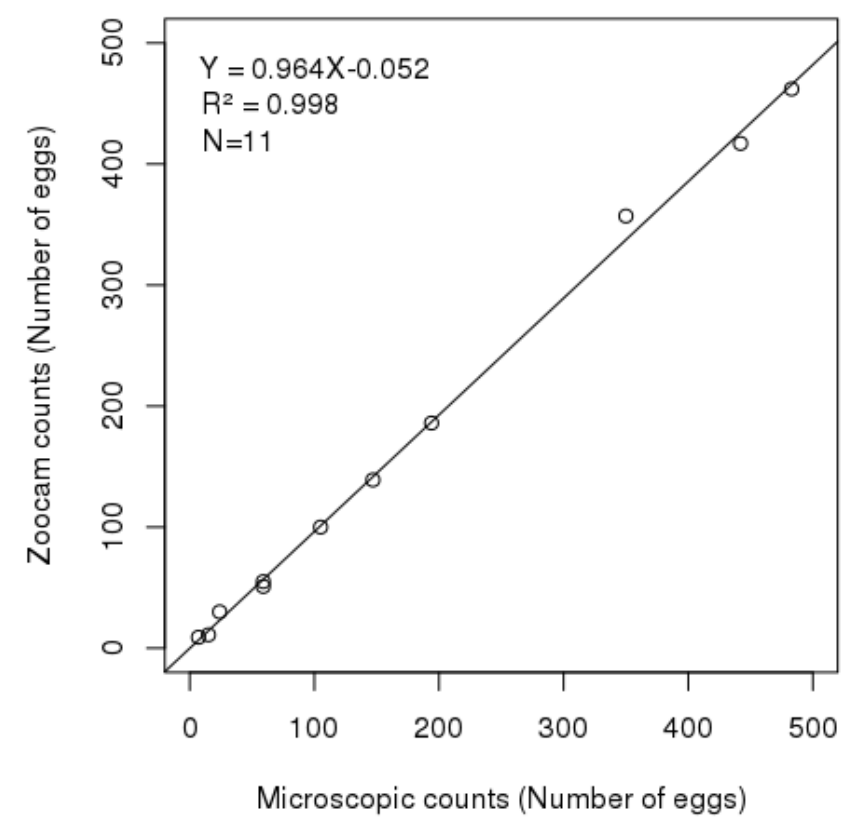

Fig.4 Regression between abundances from ZooCAM processing and dissecting microscope identification on anchovy eggs.

\section{Assessment of Touching Objects and 'Cut' objects}

The proportion of TO as a function of number of objects imaged is shown in Fig.5. The data used are 100 CUFES samples from PELGAS 2014. All the data points shown in Fig. $5(n=100)$ are below the plotted line which has a slope of $6 \%$. This plot is an illustration of the risk to get TO when analysing water samples with the ZooCAM. For a total number of imaged objects below 5000 (Fig. 5) the risk to get TO during a ZooCAM analysis is therefore below $6 \%$. It means that when analysing a sample containing a few objects to 5000 objects, the quantity of TO in the outputs would probably not exceed $6 \%$. In this study, the ZooCAM set of images used to compare with the ZooScan contained $0.7 \%$ of TO (186 out of 26303 imaged objects), well below $6 \%$. 


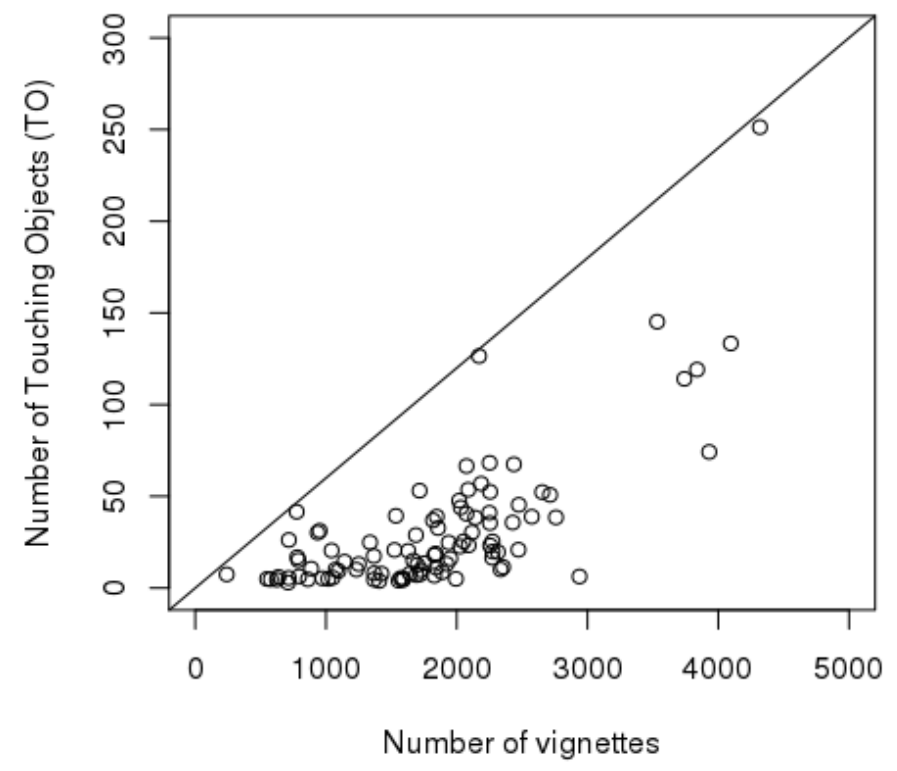

Fig. 5 Number of vignettes with TO in a dataset made of 100 CUFES samples from PELGAS 2014 cruise. Each open circle represent a sample; $x$-axis represent the number of output vignettes after ZooCAM analysis; $y$-axis represent the number of $\mathrm{TO}$ in each analysed sample. Slope of black line is 0.06 .

Concerning the risk of getting cut objects, the simulation predicted that the probability of objects to be cut increased with increasing length (Fig.6). In the 100 CUFES samples analysed to estimate the proportion of cut eggs, the average fraction of cut eggs per sample was $13.3 \%(+/-3.8$ s.d.) for anchovy and $13.92 \%$ (+/- 5.16 s.d.) for sardine. The simulation indicated $8 \%$ for anchovy eggs, which is below the lower limit of the confidence interval of the true proportion of cut eggs. In contrast, the simulation indicated $10 \%$ for sardine eggs which is well within the confidence interval of the true proportion of cut eggs (Fig.6).

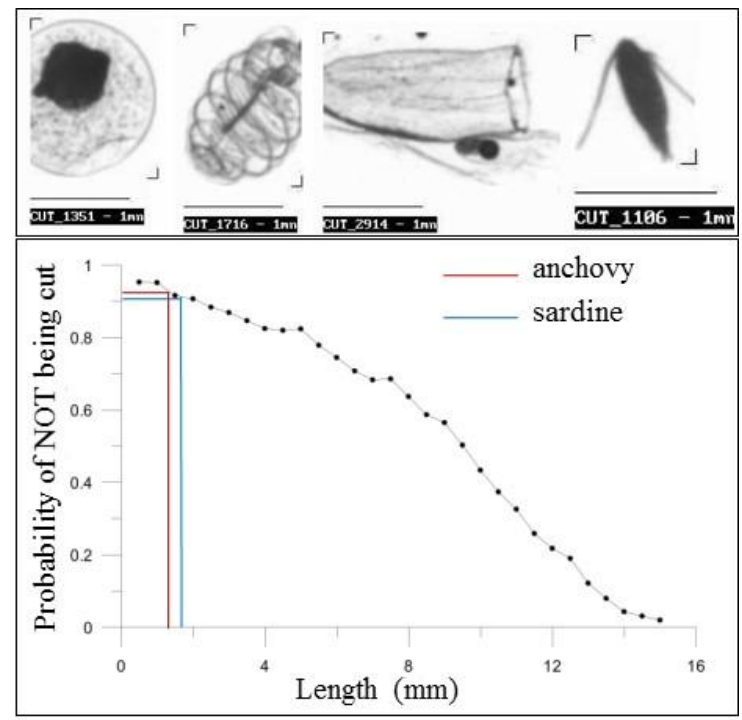

Fig. 6 Top row: Example of cut objects (Sardine egg, Doliolida, Siphonophora bell and Copepod). Bottom plot: results from simulations showing the probability of imaging a whole 
object depending on its length when it passes through the flow cell. Red line $x$-intercep $=1.4$ $\mathrm{mm}, \mathrm{y}$-intercep $=\mathbf{0 . 9 2}$; Blue line $\mathrm{x}$-intercep $=\mathbf{1 . 6} \mathrm{mm}, \mathrm{y}$-intercep $=\mathbf{0 . 9 0}$;

\section{Comparison of ZooCAM and ZooScan: FROMVAR samples}

Total plankton abundance (Fig. 7A) as estimated with the ZooScan ranged from 1949 ind.m ${ }^{-}$

${ }^{3}$ (station 15) to 6310 ind. $\mathrm{m}^{-3}$ (station 10), whereas that estimated with the ZooCAM ranged from 1654 (station 15) ind. $\mathrm{m}^{-3}$ to 4358 ind. $\mathrm{m}^{-3}$ (station 10). The abundances estimated with the ZooScan where more or less $20 \%$ higher than those estimated with the ZooCAM for the stations 10 and 27. The abundance estimated with the ZooCAM was noticeably higher than that estimated with the ZooScan only for station 16 (more or less $25 \%$ higher). ZooScan and ZooCAM total plankton abundances where very similar for the remaining stations (4, 19, 20, 25 and 31). Overall, ZooCAM and ZooScan abundances by station followed the same pattern.

Total plankton biovolume (Fig. 7B) as estimated with the ZooScan ranged from $394 \mathrm{~mm}^{3} . \mathrm{m}^{-}$ ${ }^{3}$ (station 16) to $3270 \mathrm{~mm}^{3} \cdot \mathrm{m}^{-3}$ (station 15), whereas that estimated with the ZooCAM ranged from $297 \mathrm{~mm} 3 . \mathrm{m}-3$ (station 31) to $604 \mathrm{~mm}^{3} \cdot \mathrm{m}^{-3}$ (station 15). The biovolumes estimated with the ZooScan where noticeably higher (1.5 to 2 times higher) than those estimated with the ZooCAM for the stations 4, 10, 15, 20, 25 and 27. ZooScan and ZooCAM total plankton biovolumes where similar for the remaining stations $(16,19$, and 31$)$.

The total plankton community NB-SS slopes (Fig. 7C) as estimated with the ZooScan ranged from -1.02 (station 25) to -0.61 (station 27) whereas those estimated with the ZooCAM ranged from -0.91 (station 20) to -0.69 (station 15). The slopes computed with the ZooScan data are steepest than those computed with the ZooCAM data for stations 15 and 25, flattest for stations 16 and 27, and similar for stations 4, 10, 19, 20 and 31. The ANCOVA followed by multiple pair-wise comparison between ZooScan and ZooCAM NB-SS slopes showed 2 statistically significant difference, for station 25 and 27 slopes.

The total plankton ESD distributions by stations (Fig. 7D) as estimated by the ZooScan are consistently slightly more extended toward large objects than those estimated with the ZooCAM. The total plankton ESD distributions by stations were systematically statistically different at the 5\% confidence level except for station 10 (Wilcoxon test: station 10: $n_{\text {zooscan }}=1105, n_{\text {zoocam }}=2178, p=$ 0.0789). Although ZooCAM ESD distributions medians were consistently lower than ZooScan ESD distributions medians, overall ZooCAM and ZooScan ESD distributions by station followed the same pattern. 

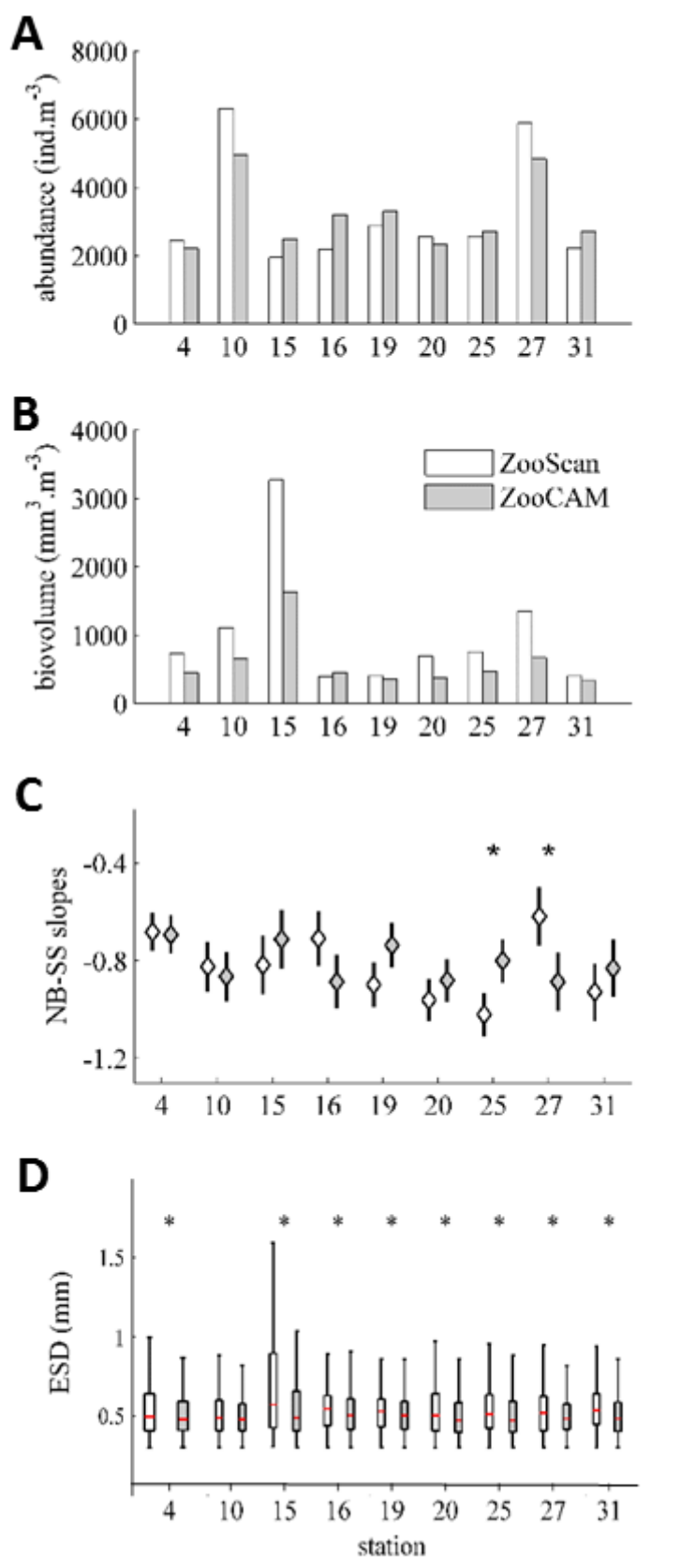

Fig. 7: Comparison of coarse quantitative descriptive variables of the whole community, station by station: A) Total planktonic abundance; B) Total planktonic biovolume; C) NB-SS slopes and $95 \%$ Confidence Interval; and D) size, measured as individual Equivalent Spherical Diameter (ESD) distributions. The red line in each box represent the median of the distribution, while the bottom and top of the box represent the first and third quartiles of the distribution, respectively. The whiskers extent represent $99.5 \%$ of the distribution. Outliers were not shown. The stars above the boxplots indicate a significant difference between the 2 datasets at the $5 \%$ significance level.

The community composition (Fig. 8) estimated as the distribution of shares of each planktonic category ( $\%$ abundance), was compared station by station. Copepoda always represent more than $75 \%$ of the community: ZooScan [77\% (station 4) - $95 \%$ (station 27)]; ZooCAM [80 \% (station 16) - $96 \%$ (station 27)] (Table 2). ZooCAM copepods shares are always slightly higher 
than those of ZooScan except for station 16 and 19 where they are slightly lower than those of ZooScan (table 2).

Some noticeable differences in the community compositions can be seen. At station 15 the proportion of Siphonophora in the ZooScan community is twice that of the ZooCAM community, and the proportion of Thaliacea in the ZooCAM community is twice that of the ZooScan community. At station 16, Appendicularia and Cladocera represent $\sim 50 \%$ of the total abundance (excluding copepods) in the ZooScan community whereas they represent more than $80 \%$ in the ZooCAM community. Overall, the station by station pair-wise Wilcoxon tests indicated that there were no statistically significant differences between the ZooScan and ZooCAM community compositions at the $5 \%$ significance level (tests statistics: station $4, n_{\text {zooscan }}=10, n_{\text {zoocam }}=10, p=1$; station $10, n_{\text {zooscan }}=10, n_{\text {zoocam }}=10, p=0.62$; station $15, n_{\text {zooscan }}=10, n_{\text {zoocam }}=10, p=0.79$; station 16 , $n_{\text {zooscan }}=10, n_{\text {zoocam }}=10, p=0.79$; station $19, n_{\text {zooscan }}=10, n_{\text {zoocam }}=10, p=0.73$; station $20, n_{\text {zooscan }}=10$, $n_{\text {zoocam }}=10, p=0.57$; station $25, n_{\text {zooscan }}=10, n_{\text {zoocam }}=10, p=0.97$; station $27, n_{\text {zooscan }}=10, n_{\text {zoocam }}=10$, $p=0.42 ;$ station $\left.31, n_{\text {zooscan }}=10, n_{\text {zoocam }}=10, p=0.79\right)$.
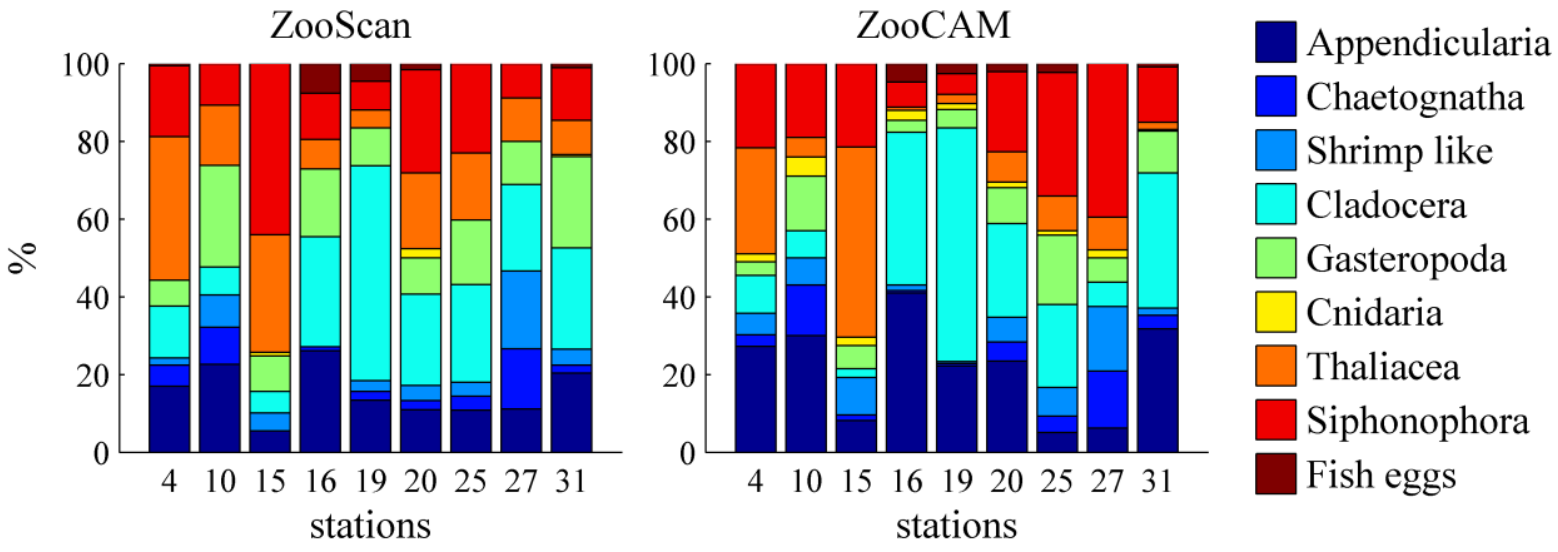

Fig. 8: Community composition as estimated from abundance data obtained with the ZooScan and the ZooCAM. The copepods share is not shown (see table 2).

Table 2: Copepods contribution to the total plankton community, expressed in \% abundance, by station.

\begin{tabular}{|l|l|l|}
\hline Station & ZooScan & ZooCAM \\
\hline 4 & 77.4 & 80.9 \\
\hline 10 & 90.1 & 92.5 \\
\hline 15 & 81.7 & 88.2 \\
\hline 16 & 82.2 & 79.9 \\
\hline 19 & 86.5 & 82.5 \\
\hline 20 & 82.6 & 88.9 \\
\hline
\end{tabular}




\begin{tabular}{|l|l|l|}
\hline 25 & 81.7 & 83.8 \\
\hline 27 & 94.9 & 95.9 \\
\hline 31 & 83.8 & 86.3 \\
\hline
\end{tabular}

Considering the whole dataset, ZooScan and ZooCAM size (ESD, Fig. 9A) distributions by planktonic category are in the same range except for Fish Eggs, where ZooCAM Fish Eggs sizes are in a much narrower and higher size range than ZooScan Fish Eggs. At first sight there is a good agreement between the 2 instruments for the size estimations of small sized organisms, i.e. median sizes were equivalent for Appendicularia, Copepoda, Cladocera and Gasteropoda. On the contrary there are more discrepancies in the size estimations of the larger organisms, i.e. Chaetognatha, Shrimps, Thaliacea and Cnidaria where the ZooScan measures larger organisms (larger median sizes), and Siphonophora and Eggs where the ZooCAM measures larger organisms (larger median sizes). Yet, ZooScan and ZooCAM organism's size distributions were statistically different for Chaetognatha, Copepoda, Shrimp-like, Cladocera, Gasteropoda, Siphonophora, Thaliacea, Siphonophora and Fish Eggs, and not statistically different for Appendicularia and Cnidaria (pair wise rank sum Wilcoxon tests).

Individual biovolumes by planktonic category (Fig. 9B) are in the same range for Appendicularia, Copepoda and Cladocera. They are higher as computed from ZooScan data for Chaetognatha, Shrimp-like, Gasteropoda and Thaliacea. They are higher as computed from ZooCAM data for Siphonophora, and Fish Eggs. As expected from the ESD distributions statistical analysis (pair wise rank sum Wilcoxon tests), organism's individual biovolumes distributions were statistically different for Chaetognatha, Copepoda, Shrimp-like, Cladocera, Gasteropoda, Siphonophora, Thaliacea, Siphonophora and Fish Eggs. On the contrary, they were similar for Appendicularia and Cnidaria. ESD and biovolume tests statistics are equivalent. (Appendicularia, $n_{\text {zooscan }}=179, n_{\text {zoocam }}=446, p=0.72$; Chaetognatha, $n_{\text {zooscan }}=42 n_{\text {zoocam }}=59, p<0.05$; Copepoda, $n_{\text {zooscan }}=7244, n_{\text {zoocam }}=12552, p<0.05$; Shrimp-like, $n_{\text {zooscan }}=48, n_{\text {zoocam }}=80, p<0.05$; Cladocera, $n_{\text {zooscan }}=305, n_{\text {zoocam }}=546, p<0.05$; Gasteropoda, $n_{\text {zooscan }}=165, n_{\text {zoocam }}=143, p<0.05$; Cnidaria, $n_{\text {zooscan }}=5, n_{\text {zoocam }}=34, p=0.19$; Thaliacea, $n_{\text {zooscan }}=195, n_{\text {zoocam }}=188, p<0.05$; Siphonophora, $n_{\text {zooscan }}=210, n_{\text {zoocam }}=302, p<0.05$; Fish eggs, $n_{\text {zooscan }}=22, n_{\text {zoocam }}=37, p<0.05$ ). 


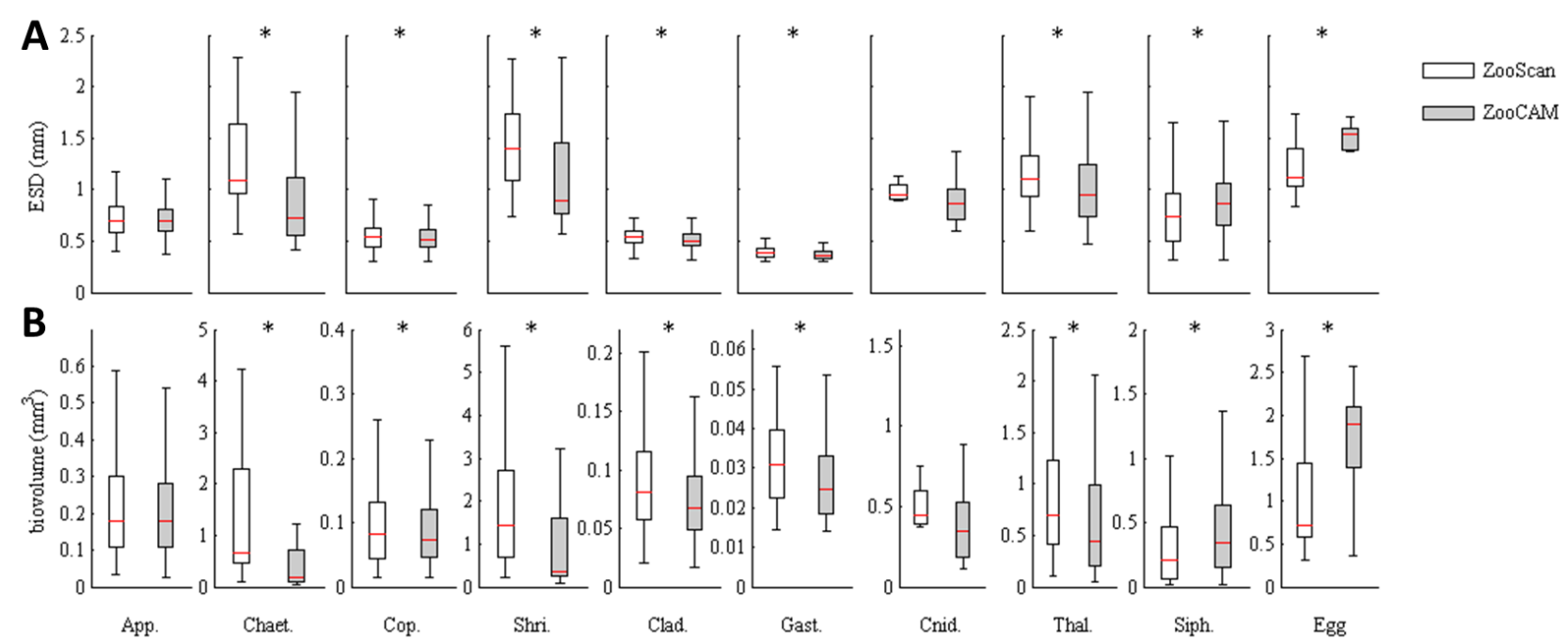

Fig. 9: A) Comparison of size (ESD) of planktonic particles, considering data pooled by organisms across the whole dataset, B) Comparison of individual biovolumes distributions of planktonic particles, considering data pooled by organisms across the whole dataset. Note the changes in $y$-axis scale in the bottom row plots. App. = Appendicularia, Chaet. = Chaetognatha, Clad. $=$ Cladocera, Cop. $=$ Copepoda, Shri. $=$ Shrimp like, Gast. $=$ Gasteropoda, Thal. $=$ Thaliacea, Cnid. $=$ Cnidaria, Siph. $=$ Siphonophora, Eggs $=$ Fish Eggs. The red line in each box represent the median of the distributions, while the bottom and top of the box represent the first and third quartiles of the distributions, respectively. The whiskers extent represent $99.5 \%$ of the distribution. Outliers were not shown.

\section{Discussion}

\section{1- Caveats and limitations of ZooCAM}

The ZooCAM is an in-flow system and encounter the same challenges as in-situ imaging systems and others in-flow imaging systems i.e. the coincidence of overlapping objects (TO) and partially imaged objects. These issues were poorly addressed in the available 'imaging for plankton' literature. One noticeable exception is the paper by Vandromme et al., (2012), which proposed an extensive review of possible biases encountered when imaging plankton with bench top scanners. TO can lead to underestimations of planktonic abundances when composed of several planktonic objects. Conversely they can end up in overestimations of biovolumes when classified into planktonic categories. In the case of benchtop plankton imaging with a scanner (i.e. ZooScan), Vandromme et al., (2012) have shown that a limited proportion of TO would have little influence on the calculated abundances of plankton. The authors also mention that $1.4 \pm 1 \%$ of surface occupied by TO over the total surface imaged (organisms and surrounding water) can have a significant effect on biovolume estimations and NB-SS and their derived parameters. However they do not mention the threshold for considering the surface occupied by TO not significant. Let's consider the 9 samples used to compare ZooScan and ZooCAM for this study. The proportion of TO varied between, $1.6 \%$ and $0.44 \%$ (abundance) at station 4 and station 31 in the ZooCAM dataset. A careful examination of the ZooCAM TO vignettes revealed that more than half of them were 
composed of either 2 planktonic objects or 1 planktonic object and 1 non planktonic object (Fig. S2 in supplementary online material). Given their proportions and their compositions we consider that TO would not significantly affect abundances estimations in our case. In addition, we could calculate that the surface occupied by TO over the total surface imaged (organisms and surrounding water), for the 9 samples, varied between $0.00050 .0025 \%$ that is 3 to 4 orders of magnitude below what Vandromme et al., (2012) observed in their experiments. Again, we consider that this negligible proportion of surface occupied by TO would not affect significantly the calculation of biovolumes and NB-SS. After these encouraging observations, TO do not seem to be an issue on this specific case. However, further tests must be done on more numerous and diverse samples to conclude firmly that TO would not be an issue with ZooCAM analyses.

When looking at Fig. 7D and Fig. 9A, it appears that very few objects in the samples were larger than $2 \mathrm{~mm}$ ESD. Hence, according to Fig. 6 the probability to get cut objects in the ZooCAM analyses is low. However, the systematic lower extent of ESD distributions by station observed for ZooCAM analyses, compared to that of ZooScan, (Fig. 7D) suggest a possible effect of the cut objects in the ZooCAM size estimations. Also, larger objects have a greater probability to be cut (Fig. 6) and an important effect on biovolume estimations (San Martin, 2005; Vandromme et al., 2012). Therefore, cut objects are likely to minor ZooCAM size distributions upper extent and biovolume estimations and induce a sensible difference between ZooScan and ZooCAM.

\section{2- ZooScan / ZooCAM comparison}

\section{Community taxonomic composition}

The community coarse taxonomic composition given by ZooCAM and ZooScan on the same nine samples are very similar regarding copepod contributions (Table 2), and other taxa contributions (Fig. 7), station by station, and are not statistically different. Observed community composition differences may be explained by identification confusions (even experts make mistakes, Culverhouse, 2007), i.e. the difference in Thaliacea and Siphonophora proportions at station 15 and 16 could be due to a confusion between these 2 large, transparent, and relatively rare organisms. When summed, the proportions of these organisms are equivalent for both stations, with both instruments. The same remark applies for the differences in Appendicularia and Chaetognatha at station 27. Appendicularia and Chaetognatha can be very lookalike on images after being processed through plankton nets, sieves and pumping systems, because very often the Appendicularia trunk is detached from its tail, which may look like a headless Chaetognatha. Besides these minor differences, ZooCAM and ZooScan outputs agreement on community composition is encouraging and suggest that at least for coarse taxonomic community or functional groups enumeration, both instruments can be used, and would give similar results. 


\section{Size distribution estimations}

Overall, the ZooScan and ZooCAM ESD distributions of total plankton community by station were similar, yet significantly different at the $5 \%$ level (Fig. 7D). As seen above, all stations were dominated by Copepoda (Table 2). A discrepancy in their individual size measurements may affect the total community size distribution. ZooScan and ZooCAM Copepoda size distributions are similar and in the same size range, although the ZooScan's seems to be a little more extended towards large objects than that of the ZooCAM (Fig. 9A). Yet Copepoda size distributions were significantly different at the $5 \%$ level. The two imaging systems capture images differently: the ZooScan make one single large image containing 1000-2000 objects, on a stable plane, where the objects are laid on the scanning tray in few milliliters of water. Even when filled with water, the ZooScan tray can be considered as a 2D plane where copepods are mostly set in a dorso-ventral position. This is the best position to capture silhouettes of organisms to measure representative body length and width or body projected area necessary to compute good estimates of individual and community size and biovolume (Vandromme et al., 2012). In contrast, the ZooCAM make successive small images of continuously flowing water containing few objects each. The water flows into a $3 \mathrm{D}, \sim 1 \mathrm{~cm}^{2}$ square section flowcell where the organisms are randomly positioned with respect to the CCD sensor plane. Silhouettes of organisms generated with the ZooCAM are not likely to be only dorso-ventral projections, but rather random projections. Nonetheless, the total plankton community NB-SS slopes tend to support the agreement between the two instrument regarding the overall estimation of community size structure (Fig. 7D). This observation is encouraging because copepod often make up most of the zooplanktonic community collected in regular plankton nets, and an agreement on the measure of size between the two instruments suggest that the ZooCAM would be suitable for size structured studies of, at least, Copepoda dominated samples.

The major differences between the 2 instruments in the estimation of size distributions were observed for the large sized functional groups (Fig. 8; Table 2). The larger the rarer in aquatic systems (Sheldon and Kerr, 1972). Reduced sampling effort or increased subsampling are likely to bias the abundance estimation of rare organisms (Gotelli \& Colwell, 2001). It follows that increasing the subsampling is likely to affect negatively the abundance estimations of large organisms, such as Chaetognatha, Cnidaria, Thaliacea, Siphonophora and Eggs. The robustness of size distributions estimations depends critically on the number of elements used to compute the size distribution. Optical and imaging techniques for counting and sizing plankton were developed also to improve our capacity to estimate robust size distributions of particles and plankton in the water (Herman, 1992; Gorsky et al., 2010). The ZooScan subsampling factors were 2 to 4 times greater 
than those of the ZooCAM (i.e. 32 for ZooCAM and 128 ZooScan). Such differences in ZooScan and ZooCAM subsampling factors may produce substantial differences on rare and large organisms' abundance, size distributions and biovolume estimations (Gotelli \& Colwell, 2001, Vandromme et $a l .$, 2012). In addition, cut objects generated by ZooCAM analyses may also reduce the upper extent (large organisms) of size distributions. Hence, it may not be relevant to conclude on the agreement or disagreement between the two instruments on the size and biovolume distributions estimations of large organisms. To reduce the subsampling effect on large bodied organisms when using a ZooScan, Gorsky et al., 2010 suggested to split the sample into two size fractions ('small' organism and 'large' organisms) prior subsampling, which implies doing 2 scans per samples, and thus multiply by 2 the time needed to process a sample. In any case, the reduced subsampling factors associated with the ZooCAM analyses accelerate significantly the analytic process, and is likely to provide more robust size distributions estimations.

\section{3- Operational validation of initial objectives}

Fast imaging and analysis of large volume samples - CUFES fish eggs

Net and CUFES sampling often lead to large number of organisms concentrated in a few hundred milliters (i.e. $250-500 \mathrm{ml}$ ) from a sampled volume in the order of $1-100 \mathrm{~m}^{3}$. During PELGAS 2016 and 2017 the actual image acquisition step never took more than 5 minutes to image a volume of 5L (source: PELGAS on-board ZooCAM logbooks). The strategy developed during PELGAS was to dedicate one operator to the sampling and practical ZooCAM operations and another person to the prediction and subsequent validation of fish eggs immediately after image processing. A fresh CUFES sample was recovered from the sampling system every 18 min, concentrated on a sieve and subsampled with a Motoda splitter (Motoda, 1959) when necessary, digitized, processed and recovered for long-term storage within more or less $10 \mathrm{~min}$. As an example, 639 CUFES samples were imaged in 32 days during PELGAS 2016, resulting in 1,212,240 objects imaged: 20 samples containing on average $~ 1900$ objects were imaged, processed and partially validated for fish eggs each day. This strategy resulted in our capacity to map at high spatial resolution the distributions of staged anchovy and sardine eggs in the Bay of Biscay on a daily basis during the cruise (Fig. S2 supplementary online materials), and to get off the cruise with a completely validated, measured and staged, anchovy and sardine eggs dataset. This is unprecedented and can be of particular interest in the case of surveys with adaptive sampling design and rapid exploitation of eggs distribution for fish stock assessment.

The closest results obtained on fish eggs with semi-automatic methods can be found in Checkley et al., 1997 who analysed 545 CUFES samples on board, in-line with an OPC. The use of OPC enabled the rapid computation of eggs size distributions on-board, but not their real time 
identification at the stage level. A few years later, an imaging instrument prototype developed to be mounted in-line with the CUFES to image fish eggs in real time on board a ship, the REFLICS, was presented (Iwamoto et al., 2001). Very interesting high resolution maps of fish eggs in the California Current were presented. However, very few literature can be found about the REFLICS, therefore it is likely that this instrument and techniques were not used later on a regular basis, probably because it did not jumped from prototype to actually usable instrument (Powell et al., 2003; Checkley and Cosman, 2004). Here, it is worth mentioning a study that showed interpolated maps of ZooScan digitized fish eggs in the North Sea based on the analysis of 1000 CUFES samples (Lelièvre et al., 2012). CUFES samples were pooled prior digitization, reducing the study spatial resolution. The ZooScan digitization process takes approximately $1 \mathrm{~h}$ per sample, in the lab on land, when the sample is divided into two size fractions, and more time to predict and validate the identifications (Romagnan et al., 2016). In the end, this method implies much further work on land, a decrease of the spatial resolution of the results, and the impossibility to have the data ready at the end of the cruise.

\section{Fish eggs detection and identification performances, measures, and ZooCAM counts}

The real time validation of staged anchovy and sardine eggs was made possible by the user friendly ZooCAM software. It enabled the complete processing of the sample from digitization to validation of predicted identifications. The algorithm used to predict identification of non-identified objects was a built-in tuned Random Forest (use of cosine similarity for discriminating each branch and leaves) which gave very good prediction rates on fish eggs similar to those found in Lelièvre $e t$ al., 2012, and higher than those found in other similar studies on plankton (i.e. Sosik and Olson, 2007; Fernandes et al., 2009; Gorsky et al., 2010; Failletaz et al., 2016; Romagnan et al., 2016). Anchovy and sardine eggs could be validated in five stages in real time, but when validation of more detailed zooplankton taxa was needed, which is the case for PELGAS WP2 samples, the validation was more time consuming and required further work back in the lab.

The good agreement between dissecting microscope counts and ZooCAM counts (Fig. 4) confirms the ZooCAM is appropriate for counting fish eggs and give data comparable to those traditionally obtained through dissecting microscope examination. Hence, using ZooCAM for fish eggs distribution studies is relevant and would not jeopardize the continuity and homogeneity of existing time series in the framework of long term monitoring (such as the PELGAS surveys). On the contrary, the difference between the size distribution and biovolume estimation between ZooScan and ZooCAM (Fig. 9) is surprising. The ZooScan has already been used to study fish eggs distributions (Lelièvre et al., 2012), and these observed differences question the ability of one or the other instrument to give reliable results on fish eggs. In the FROMVAR set of sample analysed, the 
majority of fish eggs are sardine eggs. Only a few other unidentified fish eggs were observed, and no anchovy egg was observed. Sardine eggs have a large and transparent perivitelline space, enclosed in a very thin transparent capsule. The close examination of ZooScan and ZooCAM sardine eggs vignettes reveal that ZooScan often image sardine eggs incompletely (Fig. S3 in supplementary online material). Sometimes it images only a part of the transparent capsule, without taking into account the whole perivitelline space, and totally missing the chorion; sometimes it images the chorion only, totally missing the perivitelline space and the capsule; and sometimes it images the chorion and only a part of the perivitelline space and capsule. This is probably due to the low capability of the ZooScan to efficiently capture very transparent objects. This end up in biased measures of sardine eggs sizes. These biases tend to lower the mean size of eggs and draw the size distribution of eggs towards small sizes. On the contrary, the ZooCAM captures consistently the sardine eggs in their totality (capsule + perivitelline space + chorion). Moreover, the distribution of eggs as seen by the ZooScan has of 22 data points, and that of ZooCAM 37 data points. Although the ZooScan distribution is smaller, it is also more dispersed than the ZooCAM distribution. The dispersion and mean of the two distributions tends to confirm that the measure of eggs size by the ZooCAM is more robust than that of the ZooScan. Finally, the ZooCAM mean size of eggs is in better agreement with the existing literature in the Bay of Biscay (Huret et al., 2016 measured mean fresh sardine egg diameter $=1.608 \pm 0.113 \mathrm{~mm}(n=587))$. ZooCAM mean egg size $=1.36 \mathrm{~mm}$ $(n=37)$, and ZooScan mean egg size $=1.19 \mathrm{~mm}(n=22)$. Huret et al., (2016) measured fresh sardine eggs, and formaldehyde preserved eggs were measured for this study. The difference may be due to the shrinkage caused by formaldehyde preservation (Frimpong \& Henebry, 2012).

\section{4- Perspectives and future developments}

This study showed encouraging results on the agreement between dissecting microscope and ZooCAM eggs counts, and between ZooCAM and ZooScan zooplankton community description, size measurements and counts. However, due to the small number $(n=9)$ and low diversity of samples studied, uncertainties remain and need to be clarified. A follow-up study is needed to explore in more details the differences between ZooCAM and ZooScan, based on more numerous and more diverse samples. Second, the ZooCAM generates incredible amounts of vignettes to sort and lot of validation work is needed to get taxonomically resolved zooplankton data. To increase the efficiency of the validation process a built-in link between the ZooCAM and the Ecotaxa web application (Picheral et al., 2016) is currently being developed. Ecotaxa represent a major ergonomic improvement in the management and validation of large biological image datasets. Finally, since 2016 millions of zooplanktonic objects have been imaged, described with 52 features, and identified by expert taxonomists. This represent a very valuable dataset to develop and test 
cutting edge intelligent image analysis and deep learning techniques. Collaborations are currently being set up with the deep learning community to develop plankton specific supervised learning algorithms based on the ZooCAM validated zooplankton dataset. Such developments will benefit the zooplankton community and the imaging community, and are likely to promote the analyses of the zooplanktonic compartment in ecosystemic surveys and studies.

\section{Conclusions}

The ZooCAM analyses could follow the high frequency of CUFES sampling in real time, on board. The complete processing of any sample took $\sim 10 \mathrm{~min}$, from sample retrieval to validated fish eggs counts. The ZooCAM is appropriate for the enumeration and the measurement of microorganisms > 300 microns ESD. For large concentrations of organisms and functional groups studies, ZooCAM results are likely to be better than those obtained with traditional dissecting microscope or other imaging system such as the ZooScan as a large sampled volume can be analysed and less fractionation is required, which has the effect of limiting errors on rare taxa. A special focus on fish eggs from CUFES sampling has shown that supervised classification is very efficient at the species level. Supervised classification at the stage resolution was helpful, especially for early and late stages, but significant manual validation was still necessary. However, one person dedicated to real time validation enable the generation of staged fish egg data on a daily basis. As compared to traditional manual counting with dissecting microscope, the main advantages of the ZooCAM are the use of (i) unpreserved samples (i.e. avoiding harmful chemicals as formaldehyde and shrinkage), (ii) the use of a large sample volume (i.e. large number of particles analysed to increase the robustness of measures), (iii) the use of an automatic sorting procedure, particularly efficient for fish eggs, and (iv) the rapid provision of processed data such as size structure and maps of the sampled community.

The ZooCAM can provide real time results on fish eggs and zooplankton communities, on board, either for adaptive sampling or for targeted fishing on fishery or ecosystemic surveys. Current software improvements, simplicity of use, and technical reliability already makes the ZooCAM a serious candidate for routine deployments on scientific vessels or in zooplankton labs. The ZooCAM is therefore a valuable tool to improve zooplanktonic studies, both in term of spatial coverage and temporal frequency, necessary to perform truly ecosystemic studies and monitoring in the ocean or other aquatic systems.

\section{Acknowledgments}


This study was supported by Ifremer. We want to acknowledge the joint efforts of RDT and RBE Ifremer departments in supporting the ZooCAM development. PELGAS surveys have been funded by the European Common Fishery Policy, the Marine Strategy Framework Directive, and Ifremer. We are particularly indebted with all the students, technicians and scientists who participated in the sorting of images and ran the CUFES and ZooCAM on board R/V Thalassa since 2014.

\section{References}

Ahlstrom E.1943. Studies on the Pacific pilchard or sardine (Sardinops caeculea) ;4. Influence of temperature on the rate of development of pilchard eggs in nature. U.S. Fish. Wildt. Secv.,spec. sci. rep., 23,26p.

Bachiller, E., Fernandes, J. A., Irigoien, X., 2012. Improving semiautomated zooplankton classification using an internal control and different imaging devices. Limnol. Oceanogr. Meth. 10, 1-9. doi:10.4319/lom.2012.10.1

Benfield, M.C., Grosjean, P., Culverhouse, P.F., Irigoien, X., Sieracki, M.E., Lopez-Urrutia, A., Dam, H.G., Hu, Q., Davis, C.S., Hansen, A., Pilskaln, C.H., Riseman, E.M., Schultz, H., Utgoff, P.E., Gorsky, G., 2007. RAPID Research on Automated Plankton Identification. Oceanography 20, 172-187.

Bernal, M., Stratoudakis, Y., Wood, S., Ibaibarriaga, L., Uriarte, A., Valdes, L., Borchers, D., 2011. A revision of daily egg production estimation methods, with application to Atlanto-Iberian sardine. 1. Daily spawning synchronicity and estimates of egg mortality. ICES J. Mar. Sci. 68, 519-527. doi:10.1093/icesjms/fsr001

Breiman, L., 2001. Random forests. Mach. Learn. 45, 5-32. doi:10.1023/A:1010933404324

Campbell, L., Henrichs, D.W., Olson, R.J., Sosik, H.M., 2013. Continuous automated imaging-in-flow cytometry for detection and early warning of Karenia brevis blooms in the Gulf of Mexico. Environ. Sci. Pollut. Res. 20, 68966902. doi:10.1007/s11356-012-1437-4

Certain, G., Bretagnolle, V., 2008. Monitoring seabirds population in marine ecosystem: The use of strip-transect aerial surveys. Remote Sens. Environ. 112, 3314-3322. doi:10.1016/j.rse.2008.01.019

Checkley, D.M., Ortner, P.B., Settle, L.R., Cummings, S.R., 1997. A continuous, underway fish egg sampler. Fish Oceanogr. 6, 58-73. doi:10.1046/j.1365-2419.1997.00030.x

Checkley, D.M., Cosman, P., 2004. Pelagic Fish Egg Abundance and Mortality Estimation by CUFES and Real-Time Machine Vision. California Sea Grant College Program.

Cowen, R.K., Guigand, C.M., 2008. In situ ichthyoplankton imaging system (ISIIS): system design and preliminary results. Limnol. Oceanogr. Meth. 6, 126-132.

Culverhouse, P.F., Williams, R., Reguera, B., 2003. Do experts make mistakes? A comparison of human and machine identification of dinoflagellates. Mar. Ecol. Prog. Ser., 247, 17-25.

Culverhouse, P.F., 2007. Human and machine factors in algae monitoring performance. Ecol. Inform. 2, 361-366. doi:10.1016/j.ecoinf.2007.07.001

Davis, C.S., Thwaites, F.T., Gallager, S.M., Hu, Q., 2005. A three-axis fast-tow digital Video Plankton Recorder for rapid surveys of plankton taxa and hydrography. Limnol. Oceanogr. Meth. 3, 59-74.

Doray Mathieu, Petitgas, P., Masse, J., Huret, M., Duhamel, E., Bourriau, P., Grellier, P., Dupuy, C., Van Canneyt, O., Doremus, G., 2014. The Pelgas story: from target species biomass assessment to multidisciplinary pelagic ecosystem monitoring. ICES Annual Science Conference 2014, 15 -19 September 2014, A Coruña, Spain.

Doray M., Petitgas, P., Huret, M., Duhamel, E., Dupuy, C., Romagnan, J.-B., Spitz, J., Authier, M., Sanchez, F., Berger, L., Dorémus, G., Bourriau, P., Grellier, P., Massé, J. 2017. The PELGAS survey: ship-based integrated monitoring of the Bay of Biscay pelagic ecosystem, Prog. Oceanogr. accepted.

de Fommervault, O.P., D’Ortenzio, F., Mangin, A., Serra, R., Migon, C., Claustre, H., Lavigne, H., d'Alcala, M.R., Prieur, L., Taillandier, V., Schmechtig, C., Poteau, A., Leymarie, E., Dufour, A., Besson, F., Obolensky, G., 2015. Seasonal variability of nutrient concentrations in the Mediterranean Sea: Contribution of Bio-Argo floats. J. Geophys. Res.-Oceans 120, 8528-8550. doi:10.1002/2015JC011103

Faillettaz, R., Picheral, M., Luo, J.Y., Guigand, C., Cowen, R.K., Irisson, J.-O., 2016. Imperfect automatic image classification successfully describes plankton distribution patterns. Methods in Oceanography, Computer Vision in Oceanography 15-16, 60-77. doi:10.1016/j.mio.2016.04.003

Fernandes, J.A., Irigoien, X., Boyra, G., Lozano, J.A., Inza, I., 2009. Optimizing the number of classes in automated zooplankton classification. J Plankton Res 31, 19-29. doi:10.1093/plankt/fbn098

Frimpong, E.A., Henebry, M.L., 2012. Short-Term Effects of Formalin and Ethanol Fixation and Preservation Techniques on Weight and Size of Fish Eggs. Trans. Am. Fish. Soc. 141, $1472-1479$. doi:10.1080/00028487.2012.694832

González, P., Álvarez, E., Díez, J., López-Urrutia, Á., del Coz, J.J., 2016. Validation methods for plankton image classification systems. Limnol. Oceanogr. Methods n/a-n/a. doi:10.1002/lom3.10151 
Gorsky, G., Ohman, M.D., Picheral, M., Gasparini, S., Stemmann, L., Romagnan, J.-B., Cawood, A., Pesant, S., GarciaComas, C., Prejger, F., 2010. Digital zooplankton image analysis using the ZooScan integrated system. J. Plankton Res. 32, 285-303. doi:10.1093/plankt/fbp124

Gotelli, N.J., Colwell, R.K., 2001. Quantifying biodiversity: procedures and pitfalls in the measurement and comparison of species richness. Ecol. Lett. 4, 379-391. doi:10.1046/j.1461-0248.2001.00230.x

Herman, A., 1992. Design and Calibration of a New Optical Plankton Counter Capable of Sizing Small Zooplankton. Deep-Sea Research Part a-Oceanographic Research Papers 39, 395-415. doi:10.1016/0198-0149(92)90080-D

Hirata, N.S.T., Fernandez, M.A., Lopes, R.M., 2016. Plankton Image Classification Based on Multiple Segmentations, in: 2016 ICPR 2nd Workshop on Computer Vision for Analysis of Underwater Imagery (CVAUI). Presented at the 2016 ICPR 2nd Workshop on Computer Vision for Analysis of Underwater Imagery (CVAUI), pp. 55-60. doi:10.1109/CVAUI.2016.022

Hogg, R.V., Tanis, E.A., 2006. Probability and Statistical Inference. Prentice Hall.

ICES. 2017. Report of the Working Group on Acoustic and Egg Surveys for Sardine and Anchovy in ICES Areas 7, 8, and 9. WGACEGG Report 2016 Capo, Granitola, Sicily, Italy. 14-18 November 2016. ICES CM 2016/SSGIEOM:31. 326 pp.

Iwamoto, S., Checkley, D.M., Trivedi, M.M., 2001. REFLICS: Real-time flow imaging and classification system. Mach. Vis. Appl. 13, 1-13. doi:10.1007/PL00013270

Jenkins, C.A., Goes, J.I., McKee, K., Gomes, H. do R., Arnone, R., Wang, M., Ondrusek, M., Nagamanie, P.V., Latha, T.P., Rao, K.H., Dadhwal, V.K., 2016. High-resolution shipboard measurements of phytoplankton - a way forward for enhancing the utility of satellite SST and Chlorophyll for mapping microscale features and frontal zones in coastal waters, in: Frouin, R.J., Shenoi, S.C., Rao, K.H. (Eds.), Remote Sensing of the Oceans and Inland Waters: Techniques, Applications, and Challenges. Spie-Int Soc Optical Engineering, Bellingham, p. UNSP 98780 U.

Lasker, R. 1985. An egg production method for estimating spawning biomass of pelagic fish: application to the northern anchovy (Engraulis mordax), NOAA Technical Report, NMFS 36 pg. 99 pp

Le Bourg, B., Cornet-Barthaux, V., Pagano, M., Blanchot, J., 2015. FlowCAM as a tool for studying small (80-1000 mu m) metazooplankton communities. J. Plankton Res. 37, 666-670. doi:10.1093/plankt/fbv025

Lelievre, S., Antajan, E., Vaz, S., 2012. Comparison of traditional microscopy and digitized image analysis to identify and delineate pelagic fish egg spatial distribution. J. Plankton Res. 34, 470-483. doi:10.1093/plankt/fbs015

Mannocci, L., Monestiez, P., Spitz, J., Ridoux, V., 2015. Extrapolating cetacean densities beyond surveyed regions: habitat-based predictions in the circumtropical belt. J. Biogeogr. 42, 1267-1280. doi:10.1111/jbi.12530

McClain, C.R., 2009. A Decade of Satellite Ocean Color Observations. Annu. Rev. Mar. Sci. 1, $19-42$. doi:10.1146/annurev.marine.010908.163650

Mitra, A., Castellani, C., Gentleman, W.C., Jonasdottir, S.H., Flynn, K.J., Bode, A., Halsband, C., Kuhn, P., Licandro, P., Agersted, M.D., Calbet, A., Lindeque, P.K., Koppelmann, R., Moller, E.F., Gislason, A., Nielsen, T.G., John, M.S., 2014. Bridging the gap between marine biogeochemical and fisheries sciences; configuring the zooplankton link. Prog. Oceanogr. 129, 176-199. doi:10.1016/j.pocean.2014.04.025

Motoda,S., 1959. Devices of simple plankton apparatus. Mem. Fac. Fish. Hokkaido Univ., 7, 73-94.

Moser, H., and Ahlstrom, E., 1985. Staging anchovy eggs. NOAA Technical Report, NMFS 36: $37-41$.

Olson, R.J., Sosik, H.M., 2007. A submersible imaging-in-flow instrument to analyze nano-and microplankton: Imaging FlowCytobot. Limnol. Oceanogr. Meth. 5, 195-203.

Picheral, M., Guidi, L., Stemmann, L., Karl, D.M., Iddaoud, G., Gorsky, G., 2010. The Underwater Vision Profiler 5: An advanced instrument for high spatial resolution studies of particle size spectra and zooplankton. Limnol. Oceanogr. Meth. 8, 462-473. doi:10.4319/lom.2010.8.462

Picheral M, Colin S, Irisson J-O., 2016. EcoTaxa, a tool for the taxonomic classification of images. http://ecotaxa.obsvlfr.fr

Platt, T., Denman, K., 1978. The structure of pelagic marine ecosystems. Journal du Conseil International pour l'Exploration de la Mer 173, 60-65.

Powell, J.R., Krotosky, S., Ochoa, B., Checkley, D., Cosman, P., 2003. Detection and identification of sardine eggs at sea using a machine vision system, in: Oceans 2003. Celebrating the Past ... Teaming Toward the Future (IEEE Cat. No.03CH37492). Presented at the Oceans 2003, p. 175 Vol.1-. doi:10.1109/OCEANS.2003.178544

Queste, B.Y., Fernand, L., Jickells, T.D., Heywood, K.J., Hind, A.J., 2016. Drivers of summer oxygen depletion in the central North Sea. Biogeosciences 13, 1209-1222. doi:10.5194/bg-13-1209-2016

Richardson, A.J., John, E.H., Irigoien, X., Harris, R.P., Hays, G.C., 2004. How well does the continuous plankton recorder (CPR) sample zooplankton? A comparison with the Longhurst Hardy Plankton Recorder (LHPR) in the northeast Atlantic. Deep-Sea Res. Part I-Oceanogr. Res. Pap. 51, 1283-1294. doi:10.1016/j.dsr.2004.04.002

Romagnan, J.B., Aldamman, L., Gasparini, S., Nival, P., Aubert, A., Jamet, J.L., Stemmann, L., 2016. High frequency mesozooplankton monitoring: Can imaging systems and automated sample analysis help us describe and interpret changes in zooplankton community composition and size structure — An example from a coastal site. Journal of Marine Systems. doi:10.1016/j.jmarsys.2016.03.013

Romagnan, J.-B., Legendre, L., Guidi, L., Jamet, J.-L., Jamet, D., Mousseau, L., Pedrotti, M.-L., Picheral, M., Gorsky, G., Sardet, C., Stemmann, L., 2015. Comprehensive Model of Annual Plankton Succession Based on the WholePlankton Time Series Approach. PLoS One 10, e0119219. doi:10.1371/journal.pone.0119219 
San Martin, E., 2005. Latitudinal variation in plankton size spectra along the Atlantic Ocean. University of Southampton. PhD Thesis, $162 \mathrm{pp}$.

Schofield, O., Kohut, J., Aragon, D., Creed, L., Graver, J., Haldeman, C., Kerfoot, J., Roarty, H., Jones, C., Webb, D., Glenn, S., 2007. Slocum gliders: robust and ready. J. Field Robot. 24, 473-485. doi:10.1002/rob.20200

Schultes, S., Sourisseau, M., Le Masson, E., Lunven, M., Marié, L., 2013. Influence of physical forcing on mesozooplankton communities at the Ushant tidal front. Journal of Marine Systems, XII International Symposium on Oceanography of the Bay of Biscay 109-110, Supplement, S191-S202. doi:10.1016/j.jmarsys.2011.11.025

Senn, C., Romagnan, J.B., 2017. Cartographie à haute résolution du zooplancton dans le golfe de Gascogne, par imagerie. Poster - Soutenance de Stage de Master - 22 Juin 2016, Université Pierre \& Marie Curie, Paris 6 Sorbonne Université, Fr

Sheldon, R.W., Kerr, S.R., 1972. The Population Density of Monsters in Loch Ness. Limnol. Oceanogr. 17, $796-798$. doi:10.4319/lo.1972.17.5.0796

Sieracki, C.K., Sieracki, M.E., Yentsch, C.S., 1998. An imaging-in-flow system for automated analysis of marine microplankton. Mar. Ecol.-Prog. Ser. 168, 285-296. doi:10.3354/meps168285

Sosik, H.M., Olson, R.J., 2007. Automated taxonomic classification of phytoplankton sampled with imaging-in-flow cytometry. Limnol. Oceanogr. Meth. 5, 204-216.

Stratoudakis, Y., Bernal, M., Ganias, K., Uriarte, A., 2006. The daily egg production method: recent advances, current applications and future challenges. Fish. Fish. 7, 35-57. doi:10.1111/j.1467-2979.2006.00206.x

Thyssen, M., Gregori, G.J., Grisoni, J.-M., Pedrotti, M.L., Mousseau, L., Artigas, L.F., Marro, S., Garcia, N., Passafiume, O., Denis, M.J., 2014. Onset of the spring bloom in the northwestern Mediterranean Sea: influence of environmental pulse events on the in situ hourly-scale dynamics of the phytoplankton community structure. Front. Microbiol. 5, 387. doi:10.3389/fmicb.2014.00387

Uitz, J., Claustre, H., Morel, A., Hooker, S.B., 2006. Vertical distribution of phytoplankton communities in open ocean: An assessment based on surface chlorophyll. J. Geophys. Res.-Oceans 111, C08005. doi:10.1029/2005JC003207

Vandromme, P., Stemmann, L., Garcì-Comas, C., Berline, L., Sun, X., Gorsky, G., 2012. Assessing biases in computing size spectra of automatically classified zooplankton from imaging systems: A case study with the ZooScan integrated system. Methods in Oceanography 1-2, 3-21. doi:10.1016/j.mio.2012.06.001

Zarauz, L., Irigoien, X., Fernandes, J.A., 2009. Changes in plankton size structure and composition, during the generation of a phytoplankton bloom, in the central Cantabrian sea. J. Plankton Res. 31, $193-207$. doi:10.1093/plankt/fbn 107

Zhou, M., 2006. What determines the slope of a plankton biomass spectrum? J. Plankton Res. 28, $437-448$. doi:10.1093/plankt/fbi119 